\title{
Clinical and Biochemical Assessment of Hypogonadism in Type 2 Diabetic Men
}

\author{
TALUKDER SK ${ }^{\mathrm{a}}$, AFSANA F ${ }^{\mathrm{b}}$, LATIF ZA ${ }^{\mathrm{b}}$, PATHAN F ${ }^{\mathrm{b}}$, ASHRAFUZZAMAN SM ${ }^{\mathrm{b}}$, KHAN SJ ${ }^{\mathrm{c}}$, HABIB \\ $\mathrm{SH}^{\mathrm{d}}$, SAHA S ${ }^{\mathrm{d}}$
}

\begin{abstract}
Aim: The aim of the study was to assess the prevalence of clinical hypogonadism in type 2 diabetic men based on clinical features and available biochemical measures. Materials and Methods: In this study carried out in a tertiary level hospital, serum concentration of total testosterone was measured in 170 type 2 diabetic (mean age $44.9 \pm 7.9$ years) subjects who have erectile dysfunction or other features of hypogonadism. Results: The mean total testosterone concentration in type 2 diabetic men was $14.4 \pm 5.6 \mathrm{nmol} / \mathrm{l}$. Fifty nine of 170 (34.7\%) type 2 diabetic subjects had low serum testosterone levels (d"12 nmol/L). Luteinizing hormone (LH) and follicle stimulating hormone (FSH) concentrations in type 2 diabetic men were inappropriately low with a very high prevalence of hypogonadotropic hypogonadism. BMI and waist
\end{abstract}

\section{Introduction}

Type 2 diabetes is the predominant form of diabetes worldwide, accounting for $90 \%$ of cases globally. ${ }^{1,2}$ Asian Indians have surprisingly higher prevalence of type 2 diabetes compared to Caucasians. Excessive insulin resistance in Asian Indians compared to Caucasians may be one of the contributing factors. This difference in the degree of insulin resistance may be explained by either an environmental or a genetic factor or by combination of both. ${ }^{3-10}$. Diabetes mellitus is a medical condition which is often associated with male sexual dysfunction. Erectile dysfunction (ED) is estimated to occur in $28-75 \%$ of diabetic males and its

a. Talukder SK, Department of Endocrinology, Rangpur Medical College, Bangladesh;

b. Afsana F, Latif ZA, Pathan F, Ashrafuzzaman SM, Department of Endocrinology, BIRDEM, Dhaka, Bangladesh,

c. Khan SJ, Department of Endocrinology, Enam Medical College, Savar, Bangladesh,

d. Habib SH, Saha S, Heaalth Economics Unit, BADAS, Dhaka, Bangladesh

Address of Correspondence: Dr. Samir Kumar Talukder, Diabetologist and Endocrinologist, Department of Endocrinology, Rangpur Medical College, Email: samirkumartalukder@yahoo.com; dhcdp@dab-bd.org, Cell: 01817564963

Received: May 15, 2011

Accepted: June 28, 2011 circumference were both negatively correlated with testosterone levels, with the association being stronger for waist circumference. $\mathrm{HbA}_{1} \mathrm{C}$ level also reveal a negative association with sexual dysfunction and hypogonadotropic hypogonadism among type 2 diabetic men. Metabolic syndrome is also associated with the low serum testosterone levels in the study subjects. Conclusions: This study reveals that serum total testosterone levels are lower in diabetic men with signs/symptoms of hypogonadism .Hypogonadotropic hypogonadism is frequent in diabetic hypogondal population. There is an association between poor glycaemic control and hypogonadism in male diabetic persons.

Key Words: Hypogonadism; Metabolic syndrome; Diabetes Mellitus.

(Birdem Med J 2011; 1(1): 3-9)

prevalence appears to increase with age \& duration of diabetes. ${ }^{11-14}$ The etiology of ED in type 2 diabetes is often multifactorial and include poor metabolic control, diabetes-induced micro-and macrovascular alterations, autonomic neuropathy, hypogonadism, or a combination of all these factors. ${ }^{15-17}$

Type 2 diabetes, which is not an autoimmune disorder is also associated with other endocrine diseases, in particular hypogonadism in men. Androgen deficiency has recently come to the forefront of the medical literature after being ignored for decades. Important associations are being developed and confirmed in the literature between androgen deficiency and metabolic disorders. More specifically, there is an important health impact related to metabolic syndrome (MetS), insulin resistance (IR), type 2 diabetes and ultimately vascular disease and erectile dysfunction (ED). Low concentrations of testosterone are linked with IR and implicated in hyperglycaemia, hypertension, dyslipidaemia, and an increased risk of vascular disease. ${ }^{18-23}$

Insulin resistance is an important feature of type 2 diabetes. It is being increasingly recognized that low 
testosterone levels in men are associated with reduced insulin sensitivity and type 2 diabetes. ${ }^{24}$ Serum testosterone levels are lower in a large number of Japanese patients with type 2 diabetes when compared with healthy men and suggested that testosterone supplementation in hypogonadal men could decrease IR and atherosclerosis. ${ }^{22}$ These observations suggest that androgen deficiency plays a central role in the various pathologies encompassing the components of MetS including type 2 diabetes, IR, obesity and ED.

Various guidelines for the diagnosis of hypogonadism are available. Joint guidelines for the diagnosis and treatment of men with late onset hypogonadismtestosterone deficiency associated with aging have been produced by the International Society for the Study of the Aging male (ISSAM) and the European Associatin for Urology (EAU). ${ }^{25}$ They recommend that, a total testosterome $<8 \mathrm{nmol} / \mathrm{L}$ in the presence of symptoms requires substitution and $>12 \mathrm{nmol} / \mathrm{L}$ does not. In symptomatic men with a total testosterone between 8 and $12 \mathrm{nmol} / \mathrm{L}$ trials of therapy can be considered. Both the American Association of clinical Endocrinology and the Endocrine Society recommend that the diagnosis of hypogonadism should based on low serum testosterone levels and signs / symptoms. ${ }^{26,27}$

Signs and symptoms of low testosterone levels in adults, are decreased energy level, reduced or loss of libido, diminished spontaneous erectile function, depression, poor concentration and memory, hot flushes or sweats, and infertility. ${ }^{26}$ The clinical signs of hypogonadism are usually only manifest in the more overt cases and include fine wrinkling of facial skin, eunuchoid body habitus, loss of secondary sexual hair, decreased lean body mass, increased body fat, decrease testicular volume, gynaecomastia and osteoporosis .

Current evidence shows that there is a significant proportion of men with type 2 diabetes who have hypogonadism. Although, androgen status in diabetic men is not routinely considered by the majority of medical practitioners, symptomatic patients should be considered to measure serum testosterone levels. The present study was designed to assess hypogonadism in type 2 diabetic men, referred to Endocrine Department, BIRDEM. The general objective of the study was to identify the clinical hypogonadism, based on signs / symptoms and biochemical measures available, in type
2 diabetic Bangladeshi men. The specific objectives of the study were to find out the type of hypogonadism in type 2 diabetic subjects and to find assosiation between low testosterone level and glycaemic status in type 2 diabetic subjects.

\section{Materials and Methods}

The study was conducted in the Dept. of Endocrinology, Bangladesh Institute of Research and Rehabilitation in Diabetes, Endocrine and Metabolic Disorders (BIRDEM), Dhaka, Bangladesh during the period of may 2008- April 2009.It was a cross sectional study

\section{Inclusion Criteria}

- Men with type 2 diabetes

- Age 20-55 years

- Presence of signs /symptoms that are suggestive of hypogonadism

Exclusion Criteria:

- Patients already receiving hormone replacement therapy

- Endocrine disorders other than DM

- Patients receiving any medications that may alter gonadal function

- Surgical interventions likely to impair sexual function

- Patients with liver, renal and severe heart failure

- Acute infections

\section{Study Subjects:}

Study subjects were selected purposively about 450 patients was interviewed at outdoor and indoor department of Endocrinology, BIRDEM. After taking brief history, preliminary selection was done on the basis of signs/ symptoms of hypogonadism and exclusion of other systemic illnesses. 350 patients were enlisted their name after primary selection. History taken and clinical examination performed with a pre-structured questionnaire. Next morning following an overnight (1012 hours) fast blood sample was collected. One hundred and seventy subjects were attended and investigated properly. A diagnosis of hypogonadism was made if anybody had symptoms/ signs of hypogonadism and total testosterone d" $12 \mathrm{nmol} / \mathrm{L}$. In a patient with low testosterone level LH. FSH, Prolactin and SHBG were measured for further assessment. 
Anthropometric measurements and other physical examinations:

Standing height and weight was measured using appropriate scales. Body mass index (BMI) of the subjects were calculated using the formula: $\mathrm{BMI}=$ Weight (kg)/(Height in meter) $)^{2}$.Waist circumference was measured to the nearest $0.5 \mathrm{~cm}$ with a soft nonelastic measuring tape. The tape was snug, but not so tight as to cause skin indentation or pinching. Horizontal arm span (between the out spread middle fingertips with the patient standing against a flat backboard) was measured to the nearest $0.5 \mathrm{~cm}$.Lower segment was measured from the top of the symphysis pubis vertically to the floor with the subject standing straight. Then the upper segment was determined by subtracting the lower segment from the standing height measurement noted above. Breast staging was done according to Marshal and Tanner stages of breast development. After proper exposure of the subjects, pattern of pubic hair was seen and the stage of pubic hair was determined by marshal and Tanner staging. Testicular volume was estimated with the Prader Orchidometer.The fully stretched dorsal penile length was measured in the flaccid state from the pubopenile skin junction to the tip of the glans .Subjects were requested to fast at least 10 hours and fasting venous blood sample $(10 \mathrm{ml})$ was collected between 8.00-9.00 A.M.

\section{Statistical analysis:}

Statistical analysis was performed using SPSS software for Windows Version 11.5.All data were expressed as mean with 95\% confidence interval and percentage (\%) as appropriate.

\section{Results and Observations}

A total of 170 diabetic subjects were studied.

Clinical and biochemical characteristics of study subjects.

Age (years) mean \pm SD was 44.9 \pm 7.9. Weight $(\mathrm{kg})$ mean \pm SD was 66.8 \pm 9.7 . BMI $\left(\mathrm{kg} / \mathrm{m}^{2}\right)$ mean \pm SD was 24.6 \pm 2.9 . Mean \pm SD of waist circumference $(\mathrm{cm})$ was 91.6 \pm 7.6 Mean \pm SD of systolic blood pressure (mmHg) and diastolic blood pressure $(\mathrm{mmHg})$ were $120.9 \pm 13.6$ and 79.4 \pm 7.7. Right and left testicular volume (ml)mean \pm SD were $19.5 \pm 4.4$ and 20.0 \pm 4 .2. Fasting blood glucose $(\mathrm{mmol} / \mathrm{l})$, mean $\pm \mathrm{SD}$ was $7.7 \pm 2.3$ Mean $\pm \mathrm{SD}$ cholesterol (mg/dl), TG (mg/dl), LDL (mg/dl) were
185.3 $\pm 34.9,193.2 \pm 80.8,114.0 \pm 32.6$.. Mean \pm SD of HDL (mg/dl) was $32.6 \pm 5.4$.

Serum total testosterone $(\mathrm{nmol} / \mathrm{L})$ mean \pm SD was 14.4 \pm 5.6 . Mean \pm SD of serum SHBG (nmol/L), LH $(\mathrm{mIU} / \mathrm{l}), \mathrm{FSH}(\mathrm{mIU} / \mathrm{ml})$, prolaction $(\mathrm{mIU} / \mathrm{ml})$ were $36.0 \pm 16.5,6.8 \pm 5.3,8.0 \pm 6.9,193.0 \pm 87.9$

Maximum numbers (39.4\%) of the subjects were found in the age group of 40-49 years One hundred and thirty one $(77.0 \%)$ subjects had history of regular exercise (at least 3 days a week). Alcohol consumption was very limited. History of diminished nocturnal erection was found in 166 (97.6\%) subjects. Decreased libido was found in 65(38.2\%).Fourteen (8.2\%) subjects gave history of sub-fertility.

\section{Table I}

\section{Background characteristics of study subjects}

\begin{tabular}{|c|c|c|}
\hline & $\mathrm{n}$ & $\%$ \\
\hline \multicolumn{3}{|l|}{ Age in years } \\
\hline $20-29$ & 5 & 2.9 \\
\hline 30-39 & 38 & 22.4 \\
\hline $40-49$ & 67 & 39.4 \\
\hline$\geq 50$ & 60 & 35.3 \\
\hline \multicolumn{3}{|l|}{ Exercise } \\
\hline Yes & 131 & 77.0 \\
\hline No & 39 & 23.0 \\
\hline \multicolumn{3}{|l|}{ Smoking } \\
\hline Smoker & 79 & 46.4 \\
\hline Non smoker & 91 & 53.5 \\
\hline \multicolumn{3}{|l|}{ Alcohol intake } \\
\hline Yes & 10 & 5.9 \\
\hline No & 160 & 94.1 \\
\hline \multicolumn{3}{|c|}{ Diminished nocturnal erection } \\
\hline Yes & 166 & 97.6 \\
\hline No & 4 & 2.4 \\
\hline \multicolumn{3}{|l|}{ Libido } \\
\hline Normal & 105 & 61.8 \\
\hline Decreased & 65 & 38.2 \\
\hline \multicolumn{3}{|l|}{ Sub fertility } \\
\hline Yes & 14 & 8.2 \\
\hline No & 156 & 91.8 \\
\hline \multicolumn{3}{|l|}{ Testosterone } \\
\hline$<8 \mathrm{nmol} / \mathrm{l}$ & 29 & 17.0 \\
\hline $8-12 \mathrm{nmol} / \mathrm{l}$ & 30 & 17.6 \\
\hline$>12 \mathrm{nmol} / \mathrm{l}$ & 111 & 65.3 \\
\hline
\end{tabular}




\section{Frequency of hypogonadism according to low serum total testosterone $(\leq 12 \mathrm{nmol} / \mathrm{L})$}

Subjects were divided into hypogonadal (serum total testosterone $\leq 12 \mathrm{nmol} / \mathrm{L}$ ) and eugonadal (serum total testosterone $>12 \mathrm{nmol} / \mathrm{L}$ ) according to serum total testosterone level. Out of which 59 (34.7\%) had hypogonadism. Hypogonadism was classified according to $\mathrm{LH}$ concentration ( $<50 \%$ of normal range was classified as lower level). In this way hypogonadotropic hypogonadism was found in 34(57.6\%). Normogonadotropic hypogonadism and hypergonadotropic hypogonadism was found $17(28.8 \%)$ and $8(13.6 \%)$ respectively. In this observation hypogonadotropic hypogonadism was found more in study subjects.

Comparison of clinical and biochemical characteristic of study subjects with normal or low total testosterone.

Age (years) as mean \pm SD of hypogonadal (low total testosterone) and eugonadal (normal total testosterone) study subjects were $43.9 \pm 7.4$ and $45.5 \pm 8.1$ respectively and did not different significantly $(\mathrm{p}=0.223)$. Duration of diabetes (years) in hypogonadal and eugonadal subjects were $5.2 \pm 4.4$ and $6.1 \pm 5.1$ respectively, not significantly $(\mathrm{p}=0.227)$ different. BMI $\left(\mathrm{kg} / \mathrm{m}^{2}\right)$, waist circumference (cm) were $24.8 \pm 2.9,93.1 \pm 6.9$ in hypogonadal subjects and $24.5 \pm 2.8,90.7 \pm 7.9$ in eugonadal subjects respectively. Right sided testicular volume (ml) was significantly ( $\mathrm{p}=0.023$ ) different in two groups; $19.0 \pm 4.7$ vs 20.6 \pm 3.8 in hypogonadal vs eugonadal subjects respectively. Left sided testicular volume $(\mathrm{ml})$ was $18.1 \pm 5.1$ and $20.3 \pm 3.8$ respectively, there was also significant $(p=0.002)$ difference in two groups. In hypogonadal subjects $\mathrm{HbA}_{1} \mathrm{C}$ level was found significantly $(\mathrm{p}=0.001)$ higher than the eugonadal subjects [ $8.9 \pm 1.6$ and $7.8 \pm 1.3$ respectively]. Among the four components of lipid profile, serum TG (mg/dl) was significantly $(p=0.031)$ different in two groups. [211.1 \pm 81.5 vs $183.5 \pm 79.0$ in hypogonadal vs eugonadal subjects]. Mean \pm SD of cholesterol, LDL, HDL were $192.4 \pm 36.8,117.8 \pm 31.9,32.1 \pm 5.4$ in hypogonadal subjects and $181.6 \pm 33.5,112.0 \pm 29.8,32.8 \pm 5.4$ in eugonadal subjects respectively. Serum total testosterone (nmol/l) as mean \pm SD in hypogonadal subjects was 9.5 \pm 1.8 , whereas in eugonadal subjects was $18.6 \pm 4.1$. Serum SHBG (nmol/l), and prolactin (mIU/ml) level were not significantly different between the hypogonadal and eugonadal subjects . Serum LH and FSH (mIU/ml) was significantly $(\mathrm{p}=0.001, \mathrm{p}=0.020)$ lower in hypogonadal subjects than the eugonadal subjects .

In this study, there was significant difference in testicular volume, $\mathrm{HbA}_{1} \mathrm{C}$ level, serum TG, total testosterone, and LH , FSH level between the hypogoadal and eugonadal subjects.

Table II

Comparison of clinical and biochemical characteristic of subjects with normal (eugonadal) or low (hypogonadal) total testosterone.

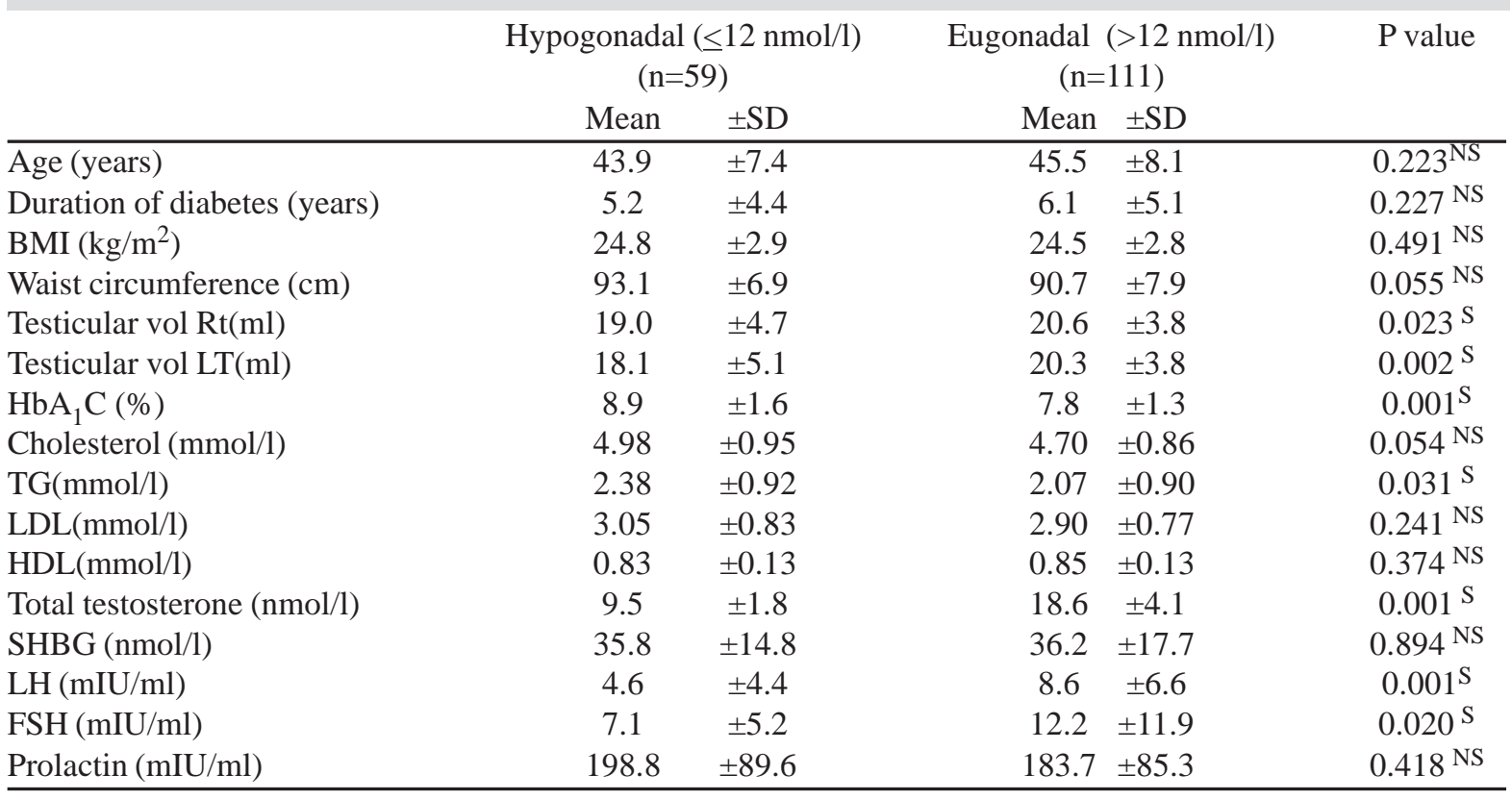




\section{Past medical history of study subjects}

Past history of hypertension was found $33.9 \%$ and $24.5 \%$ of hypogonadal and eugonadal subjects respectively. Previous history of coronary artery disease (CAD) was found $2.7 \%$ of eugonadal subjects. Both hypertension and CAD were found $1.8 \%$ of eugonadal subjects. But in majority of the subjects (66.1\% of hypogonadal and $70.9 \%$ eugonadal), no significant past illness was found.

Distribution of hypogonadism among the study subjects according to different age groups

Maximum subjects were found 40-49 years age group. Fifty or more than 50 age group were $17(28.8 \%)$ and 20-29 years age group was $1(1.7 \%)$.

Association of low testosterone levels with clinical variables in study subjects $(\mathrm{n}=170)$

BMI $>25\left(\mathrm{~kg} / \mathrm{m}^{2}\right)$ was found in 32(54.2\%) hypogonadal subjects and 47(42.3\%) eugonadal subjects. Waist circumference WC e" $90 \mathrm{~cm}$ was found in 53(89.8\%) hypogonadal subjects and 71(64.0\%) eugonadal subjects. Hypertension was found in 28(47.5\%) hypogonadal subjects and 44(39.6\%) eugonadal subjects. History of smoking was found in 23(39.0\%) hypogonadal subjects and 56(50.5\%) eugonadal subjects. History of regular exercise was found in 47(79.7\%) hypogonadal and 84(75.7\%) eugonadal subjects. History of alcohol ingestion was found in 5(8.5\%) hypogonadal and 5(4.5\%) eugonadal subjects. Sensory neuropathy was found in 8(13.6\%) hypogonadal and 23(20.7\%) eugonadal subjects.

\section{Table III}

Association of low testosterone levels with clinical variables in study subjects $(n=170)$

\begin{tabular}{lccccc} 
& \multicolumn{2}{c}{$\begin{array}{c}\text { Hypogonadal } \\
(\mathrm{n}=59)\end{array}$} & \multicolumn{2}{c}{$\begin{array}{c}\text { Eugonadal } \\
(\mathrm{n}=111)\end{array}$} & $\mathrm{P}$ \\
& $\mathrm{n}$ & $\%$ & $\mathrm{n}$ & $\%$ & \\
& & & \\
& & & & & \\
BMI $>25\left(\mathrm{~kg} / \mathrm{m}^{2}\right)$ & 32 & 54.2 & 47 & 42.3 & $0.138^{\mathrm{NS}}$ \\
WC e” $90 \mathrm{~cm}$ & 53 & 89.8 & 71 & 64.0 & $0.001^{\mathrm{S}}$ \\
Hypertension & 28 & 47.5 & 44 & 39.6 & $0.326^{\mathrm{NS}}$ \\
Smoking & 23 & 39.0 & 56 & 50.5 & $0.153^{\mathrm{NS}}$ \\
Exercise & 47 & 79.7 & 84 & 75.7 & $0.556^{\mathrm{NS}}$ \\
Alcohol intake & 5 & 8.5 & 5 & 4.5 & $0.236^{\mathrm{NS}}$ \\
Sensory neuropathy & 8 & 13.6 & 23 & 20.7 & $0.249^{\mathrm{NS}}$ \\
\hline
\end{tabular}

Association of metabolic syndrome and hyogonadism among the study subjects
Metabolic syndrome was present in 52 (88.1\%) and $67(60.4 \%)$ in hypogonadal and eugonadal subjects. The difference was statistically significant $(p=0.001)$ in between the hypogonadal and eugonadal subjects.

Relationship of glycaemic status $\left(\mathrm{HbA}_{1} \mathrm{C}\right)$ to distribution of hypogonadism in study subjects

In diabetic hypogonadal subjects ( $\mathrm{n}=59), 13(22.0 \%)$ had good glycaemic status $\left(\mathrm{HbA}_{1} \mathrm{C}<7 \%\right)$ and 46 (88.0\%) had poor glycaemic status $\left(\mathrm{HbA}_{1} \mathrm{C}>7 \%\right)$. $\mathrm{HbA}_{1} \mathrm{C} 7.1-$ $8 \%$ was found in $15(25.4 \%)$, 8.1-9\% was found in 12(20.3\%), 9.1-10\% was found in $9(15.3 \%)$ and $>10 \%$ was found in $10(16.9 \%)$ of hypogonadal subjects. This study showed higher percentage of hypogonadal subjects had poor glycaemic control.

\section{Correlation of BMI , waist circumference and with $\mathrm{HbA}_{1} \mathrm{C}$ total testosterone}

Total testosterone was correlated inversely with BMI and waist circumference in study subjects. Total testosterone was negatively correlated with $\mathrm{HbA}_{1} \mathrm{C}$ level in study subjects.

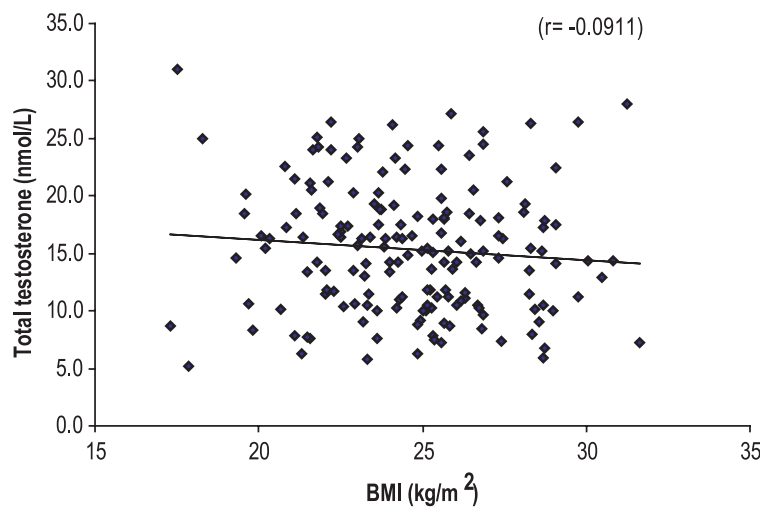

Fig. 1: Correlation of BMI and total testosterone in study subjects

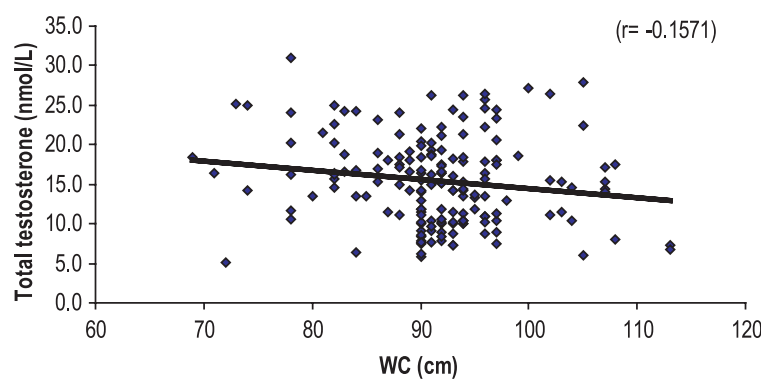

Fig. 2: Correlation of waist circumference and total testosterone in study subjects 


\section{Discussion}

Previous studies ${ }^{19}$ showed that about one third of type 2 diabetic men have low serum testosterone levels, but these studies had not correlated this value with symptoms. The present study clearly shows that there is a high prevalence of symptomatic hypogonadism in men with type 2 diabetes.

In the Baltimore longitudinal study on aging 8, 12, 19 and $28 \%$ of men aged $>40,50,60$ and 70 years, respectively, had serum total testosterone levels below the normal range ${ }^{28}$. In the present study, the mean total testosterone levels in diabetic men were also progressively lower in higher age groups. The frequencies of hypogonadal symptoms were similar in all age-groups of low testosterone in the present study and supported the similar results found in a previous study. ${ }^{29}$

Gonadotropin Concentrations were not elevated in most of the hypogonadal subjects of type 2 diabetes in present study, and thus the primary defect in these patients would appear to be either in the pituitary gland or hypothalamus. In fact, the LH and FSH levels were significantly lower in the hypogonadal group than the eugonadal group. To rule out the possibility that the cause of hypogonadotropic hypogonadism was a pituitary lesion, MRI of pituitary and perisellar region was done in 15 randomly selected hypogonadal subjects. None of the MRIs showed pituitary or hypothalamic abnormalities. Previously in a study, it was similarly found high prevalence of hypogonadotropic hypogonadism in type 2 diabetes. 19

In this study, testosterone level is inversely correlated with waist circumference and BMI. A Possible explanation for this is the hypogonadal obesity cycle. ${ }^{30}$ Essentially, visceral adipocytes have a high activity of the enzyme aromatase which converts testosterone to estrogen. Testosterone inhibits the enzyme lipoprotein lipase, which takes up free fatty acids into adipocytes. Lower levels of testosterone result in increased triglyceride levels in adipocytes, which promote further adipocyte proliferation and hence higher aromatase activity. In this study, it was also shown that serum total testosterone negatively correlated with $\mathrm{HbA}_{1} \mathrm{C}$ level. This observation may suggest relation of hypogonadism to poor glycaemic control.

Serum testosterone levels have been reported to be lower in men with hypertension. ${ }^{31}$ But the present study did not show a significant association between testosterone levels and history of hypertension. Similarly, this study found no significant association between testosterone levels and smoking. The majority of cross- sectional studies have shown that low testosterone levels are associated with a pro-atherogenic lipid profile high total and LDL cholesterol and triglycerides (TG) and low HDL cholesterol ${ }^{32}$. In this study, high TG and low HDL were found more in hypogonadal subjects than the eugonadal subjects, but the total cholesterol and LDL cholesterol did not vary between the two groups.

In this study, higher prevalence of metabolic syndrome (according to IDF criteria) was found among the hypogonadal subjects. Different components of metabolic syndrome were also significantly higher among the hypogonadal subjects than the eugonadal subjects. These observations suggest that androgen deficiency plays a central role in the various pathologies encompassing the components of metS including central obesity, insulin resistance, hyperglycaemia, dyslipidaemia and hypertension.

\section{Conclusion:}

This study reveals that serum total testosterone levels are lower in diabetic men with signs/symptoms of hypogonadism .Hypogonadotropic hypogonadism is frequent in diabetic hypogondal population. There is an association between poor glycaemic control and hypogonadism in male diabetic persons.

\section{Acknowledgement}

We are thankful to all the study participants and Department of Endocrinology for their kind support throughout the study period.

\section{Disclosure:}

We did not get any type of financial support from anywhere at home or abroad.

There is no conflict of interest.

\section{References}

1. Zimmet P, Alberti KG, Shaw J (2001): Global and societal implications of the diabetes epidemic Nature 414: 782-87.

2. King H, Aubert RE, Hermon WH (1998): Global burden of diabetes, 1995-2025: prevalence, numerical estimates and projections. Diabetes Care 21: 1414-31.

3. Abate N. Chardalia m (2001). Ethnicity and type 2 diabetes: Focus on Asian Indians. J Diabetes Complications, 15; 320 7. 
4. Dhawan J, Bray CL, Warburton R, Ghambhir Ds, Moris J ( 1994): Insulin resistance, high prevalence of diabetes and Cardiovascular risk in immigrant Asians, Genetic or environmental effect? Br Heat J 72; 413-21.

5. Gopalan c (2001) : Rising incidence of obesity, coronary heart disease and diabetes in the Indian Urban Middle class. Possible role of genetic and environmental factors. World Rev Nutr Diet 90; 127-43.

6. Mohan V (2004): Why are Indians More Prone to Diabetes? JAPI, 52 : 468-74.

7. Radha V, Vimaleswaran KS, Deepa R, Mohan V (2003); The generics of diabetes mellitus. Indian J Med Res117: 225-38

8. Ramachandran A, Snehalatha C, Baskar ADS, Mary S, Sathish Kumar Ck, Selvam S, Catherine S. Visay V (2004) : Temporal changes in prevalence of diabetes and impaired glucose tolerance associated with life style transition occuring in the rural population in India. Diabetologia 47: 860-65

9. Ramachandran A (2005) : Epidemiology of Diabetes in IndiaThree Decades of Research. JAPI 53 : 34-38

10. Snehalatha C, Ramachandran A, Kapur A, Vijay V (2003): Age- specific prevalence and Risk Associations for Impaired Glucose Tolerance in Urban Southern Indian Population. JAPI 51: 766-69.

11. Feldman HA, Goldstein I, Hatzichristou DG. Krane RJ, Mckinlay JB (1994): Impotence and its medical and physiological correlates: results of the Massachusetts Male Ageing Study. J Urol 151 : 54-61.

12. Fedele D, Bortolotti A, Coscelli C, Santeusanio F, Chatenoud L, Clli E, et al. (2000) : Erectile dysfunction in type-1 and type-2 diabetes in Italy. Int J Epidemiol 29: 524-31.

13. Carlin BW (1988) : Impotence and diabetes. Metab Clin Exp 37 ( suppl 2): 19-21

14. Kaiser FE, Korenman SG ( 1988) : Impotence in diabetic men. Am J Med. 85: 147-52

15. Fedele D, Coscetti C, Santeusanio F, Bortolotti A, Chatenoud L, Colli E et al( 1998); Erectile dysfunction in diabetic subjects in Italy.Gruppo Italiano Studio Deficit Erettile nei diabeticI. Diabetes Care 21: 1973-77.

16. Popivanob P , Protich M, Manolov D, Velichkov P, Lazarov G ( 1994) : Autonomic neuropathy and erectile dysfunction in diabetic patients. Medicographia 16 ( suppl 1) : 94-5

17. Dunsmuir WD, Holmes SA ( 1996) : The etiology and management of erectile, ejaculatory and fertility problems in men with diabetes mellitus. Diabet Med 13: 700-8

18. Simin D, Charles MA, Nahoul K Orssaud G, Kremski J, Hilly V, Joubert E, Papoz L, Eschewed E (1997) : Association between plasma total testosterone and cardiovascular risk factor in healthy adult men: The Telecom Study . J Clin Endocrinol Metab. 82: 682-85.
19. Dhindsa S, Prabhakar S, Setti M, Bandyopadhyay A, Chaudhuri A, Dsandona P ( 2004); Frequent occurrence of hypogonadotropic hypogonadism in type-2 diabetes. J Clin Endocrinol Metab : 5462-68

20. Pitteloud N, Hardin M, Dwyer AA, Valassi E, Yialamas M, Elkali D, Hayes FJ (2005 a) : Increasing insulin resistance is associated with a decrease in Leydig cell testosterone secretion in men. J clin Endocrinol Metab 90: 2636-41

21. Rhoden EL, Ribeiro EP, Teloken C, Souto CA (2005 b) : Diabates mellitus is associated with subnormal serum levels of free testosterone in men. BJU Int 96: 867-70

22. Fukui M, Soh J, Tanaka M,Kitagawa Y, Hasegawa G, Yoshikawa T. Nakamura N ( 2008): Association between serum bioavailable testosterone concentration and the ratio of glycated hemoglobin in men with type -2 diabetes.Diabetes Care 31: 397-401.

23. Selvin E, Feinleib m, Zhang L, Rohrmann S, Rifai N, Nrlson W, Dobs A, Bayaria S, Golden S, Platz E (2007) | Androgens and diabetes in men. Diabetes Care 30 : 234-38.

24. Kapoor D, Maldin CJ, Channer KS Jones TH (2005) : Androgens, insulin resistance and vascular disease in men. Clin. Endocrinol, (oXf) 63: 239-50.

25. Nieschlag E, Swerdloff R, Behre HM. et al (2006) Investigation, treatment and monitoring of late onset hypogonadism in males : ISA, ISSAM and EAU recommendations. J Androl 27: 135-37

26. Bhasin S, Cunningham GR, Hayes FJ, Matsumoto AM, Snyder PJ, Swerdloff RS, Montri vm (2006) : Testosterone therapy in adult men with androgen deficiency syndromes : An Endocrine Society Clinical Practice Guideline. J clin Endocrinol metab 91 : 1995-2010.

27. Petak SM, Nankin HR, Spark RF et al. (2002) American association of Clinical Endocrinologists medical guidelines for clinical practice for the evaluation and treatment of hypogonadism in adult male patients- 2002 update. Endocrine Pract. 8 (6): 439-56

28. Harman SM, Metter EJ, Tobin JD et al (2001) : Longitudinal effects of aging on serum total and tree testosterone levels in healthy men. J Clin Endicrinol Metab 86: 724-31.

29. Kapoor D, Aldred H, Clark S , Channer K ,Jones T ( 2007): Clinical and biochemical assessment of hypogonadism in men with type-2 diabetes.Diabetes Care 30: 911-17.

30. Cohen PG (1999) The hypogonadal - obesity cycle. Med Hypotheses 52: 49-51

31. Phillips GB, Jing TY, Resnuck LM, et al (1993): Sex hormones and hemostatic risk factors for coronary heart disease in men with hypertension. J Hypertension11: 699-702

32. Jones RD, Nettleship JE, Kapoor D et al (2005): Testosterone and atherosclerosis in aging men. Purported association and clinical implication. Am J Cardiovas Drugs 5: 141-54. 